\title{
Impact of secondary gas-phase reactions on microcrystalline silicon solar cells deposited at high rate
}

\author{
G. Parascandolo, ${ }^{\text {a) }}$ R. Bartlome, G. Bugnon, T. Söderström, B. Strahm, A. Feltrin, and \\ C. Ballif \\ Photovoltaics and Thin Film Electronics Laboratory, Institute of Microengineering (IMT), Ecole \\ Polytechnique Fédérale de Lausanne (EPFL), Rue A.-L. Breguet 2, 2000 Neuchâtel, Switzerland
}

(Received 1 April 2010; accepted 19 May 2010; published online 9 June 2010)

\begin{abstract}
The role of secondary gas-phase reactions during plasma-enhanced chemical vapor deposition of microcrystalline silicon is a controversial subject. In this paper, we show that the enhancement of such reactions is associated with the improvement of material properties of absorber layers deposited at high constant rate. We detect powder, a product of secondary gas-phase reactions, via infrared laser absorption spectroscopy, laser light scattering, and optical emission spectroscopy. As the powder formation is increased, we measure a systematic improvement of device performance. This demonstrates that secondary gas-phase reactions are not detrimental to the material quality of microcrystalline silicon deposited at high rate. (C) 2010 American Institute of Physics.
\end{abstract}

[doi:10.1063/1.3449571]

Thin-film silicon solar cells are today a competitive alternative to traditional wafer-based photovoltaic technologies. Initial conversion efficiencies of over $13 \%$ have been demonstrated $^{1}$ for module-size tandem devices combining amorphous silicon (a-Si:H) and microcrystalline silicon ( $\mu \mathrm{c}-\mathrm{Si}: \mathrm{H})($ Ref. 2$)$ solar cells. Nevertheless, the high cost of the equipment still accounts for around 30\% of the total module cost. Increasing the throughput while keeping high conversion efficiency is the key to reduce cost. Currently, thick $\mu \mathrm{c}-\mathrm{Si}: \mathrm{H}$ absorber layers, of about $2 \mu \mathrm{m}$, are usually deposited in production lines at rates of 2.5 to $5 \AA$ 解. Highrate deposition of device-grade $\mu \mathrm{c}-\mathrm{Si}: \mathrm{H}$ is, thus, one of the most important technological challenges in view of low manufacturing costs of thin-film silicon solar cells. This goal can be achieved by plasma-enhanced chemical vapor deposition (PECVD) of $\mu \mathrm{c}-\mathrm{Si}: \mathrm{H}$ films using a very-high excitation frequency (VHF) (Refs. 3-5) and a narrow interelectrode gap. ${ }^{6,7}$ For this purpose, a high radical density in the gas-phase of the plasma must be realized. Nevertheless, as soon as this condition is met, secondary gas-phase reactions, which do not contribute to the film growth, gain in importance. Among such gas-phase reactions, we mention $\mathrm{SiH}_{2}$ $+\mathrm{SiH}_{4} \rightarrow \mathrm{Si}_{2} \mathrm{H}_{6}$ that triggers the formation of powder. ${ }^{8}$ Therefore, powder can be considered as an indicator of secondary gas-phase reactions.

Many studies have reported a drop in the quality and in the performance of $\mu \mathrm{c}-\mathrm{Si}: \mathrm{H}$ material and solar cells when the deposition rate of the absorber layer, $R_{\mathrm{d}}$, is increased. ${ }^{5,9-11}$ While the detrimental effect of strong ion bombardment ${ }^{5,10,12}$ and of insufficient relaxation of growth precursors ${ }^{11}$ have been well assessed, the role of powder is still controversial. Powder is identified as a possible additive source for the deterioration of device performance, ${ }^{5,9}$ and precautions are often taken to reduce its formation. On the other hand, it has been shown that the formation of powder under certain conditions is beneficial to the deposition of a-Si:H and $\mu \mathrm{c}-\mathrm{Si}: \mathrm{H} .{ }^{13,14}$ However, a systematic study of the effect of powder on the material quality of $\mu \mathrm{c}-\mathrm{Si}: \mathrm{H}$ films, per-

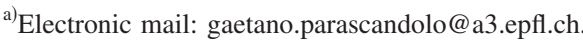

formed at a constant ion bombardment and a constant $R_{\mathrm{d}}$, is still lacking.

In this paper, we show that the formation of powder in its early stage is not detrimental to the deposition of devicequality $\mu \mathrm{c}-\mathrm{Si}: \mathrm{H}$ at high rate. We deposited $\mu \mathrm{c}-\mathrm{Si}: \mathrm{H}$ intrinsic layers (i-layers) using both dusty and nearly powder-free processes $(i)$ at a fixed pressure, (ii) at a fixed excitation frequency, and (iii) at a constant $R_{\mathrm{d}}=10 \AA / \mathrm{s}$. Conditions $(i)$ and (ii) result in comparable ion bombardment of the growing film. Condition (iii) ensures a comparable impingement rate and diffusion length of film precursors on the surface of the growing film. Therefore, these conditions enable us to isolate the effect of powder on the material quality of the deposited films. We present the results of in situ monitoring of plasma and powder dynamics during the film deposition. We then discuss the device performance of $\mu \mathrm{c}-\mathrm{Si}: \mathrm{H}$ solar cells. We deposited $\mu \mathrm{c}-\mathrm{Si}: \mathrm{H}$ p-i-n junctions in a mediumsize $\left(50 \times 60 \mathrm{~cm}^{2}\right)$ and narrow gap $(13 \mathrm{~mm})$ version of the industrial large-area VHF-PECVD KAI ${ }^{\mathrm{TM}}$ (Ref. 15) reactor, operated at $40.68 \mathrm{MHz}$. We prepared solar cells and measured their electrical and optical performance as in Ref. 16. Thick $\mu \mathrm{c}-\mathrm{Si}: \mathrm{H}$ i-layers $(1.8 \mu \mathrm{m})$ were deposited using a constant pressure $p=4.5 \mathrm{mbar}$ and a constant input silane flow, $\left[\mathrm{SiH}_{4}\right]$, while the input hydrogen flow, $\left[\mathrm{H}_{2}\right]$, was reduced from process A to E. In Table I, we report only the variation in the input silane concentration $c$, where $c$ $=\left[\mathrm{SiH}_{4}\right] /\left(\left[\mathrm{SiH}_{4}\right]+\left[\mathrm{H}_{2}\right]\right)$. In our study, $c$ increases as the total

TABLE I. Input silane concentration $(c)$, ILSS measurements $\left(\eta, c_{\mathrm{p}}\right.$, and $\left.R_{\mathrm{d}}^{\mathrm{e}}\right)$, profilometric measurement $\left(R_{\mathrm{d}}\right)$ and LLS measurement for processes A to $\mathrm{E}$.

\begin{tabular}{ccccccc}
\hline \hline Process & $\begin{array}{c}c \\
(\%)\end{array}$ & $\begin{array}{c}\eta \\
(\%)\end{array}$ & $\begin{array}{c}c_{\mathrm{p}} \\
(\%)\end{array}$ & $\begin{array}{c}R_{\mathrm{d}}^{\mathrm{e}} \\
(\AA / \mathrm{s})\end{array}$ & $\begin{array}{c}R_{\mathrm{d}} \\
(\AA / \mathrm{s})\end{array}$ & $\begin{array}{c}\text { LLS } \\
(\mathrm{mV})\end{array}$ \\
\hline $\mathrm{A}$ & 4.58 & 75.1 & 1.1 & 13.6 & 9.7 & 43.6 \\
$\mathrm{~B}$ & 5.66 & 77.6 & 1.3 & 14.0 & 10 & 73.0 \\
$\mathrm{C}$ & 6.98 & 80.2 & 1.4 & 14.5 & 10 & 114.3 \\
$\mathrm{D}$ & 9.09 & 81.8 & 1.7 & 14.8 & 10 & 136.4 \\
$\mathrm{E}$ & 13.04 & 86.6 & 1.8 & 15.7 & 10 & 267.6 \\
\hline \hline
\end{tabular}




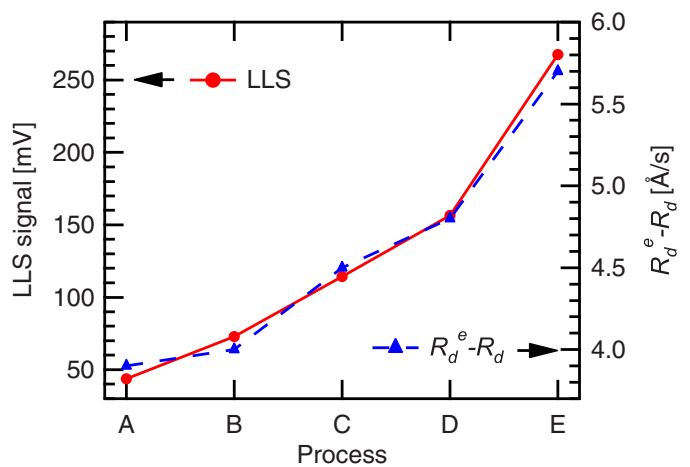

FIG. 1. (Color online) Quantification of powder by ILSS and LLS. Processes A to E correspond to the deposition of $\mu \mathrm{c}-\mathrm{Si}: \mathrm{H}$ absorber layers at $10 \AA / \mathrm{s}$. Lines are guides for the eye.

input gas flow decreases. We further adjusted the feed-in power density, $P_{\mathrm{d}}$, by a few percent to obtain films with comparable Raman crystalline fraction. The influence of the small variation in $P_{\mathrm{d}}$ on the ion bombardment is negligible. During the deposition of the i-layers, we characterized the plasma dynamic via infrared laser absorption spectroscopy. A high spectral resolution $\left(0.001 \mathrm{~cm}^{-1}\right)$ infrared laser-based silane sensor (ILSS) developed in house ${ }^{17}$ allowed us to monitor the silane dissociation efficiency, $\eta$. From the measurement of $\eta$, we determined the silane concentration in the plasma, $c_{\mathrm{p}}{ }^{18}$ and estimated the film deposition rate, $R_{\mathrm{d}}^{\mathrm{e}}$, in the hypothesis that all the dissociated silane contributed to the deposition of a uniform film. ${ }^{17}$ The actual $R_{\mathrm{d}}$ was determined by measuring the thickness of the film via profilometry. $R_{\mathrm{d}}^{\mathrm{e}}-R_{\mathrm{d}}$ is an indirect quantification of the powder produced during the PECVD process. Simultaneously to the ILSS measurement, we monitored the production of powder at the gas exhaust via visible laser light scattering (LLS) (Ref. 19) and in the reactor via optical emission spectroscopy (OES). The ILSS, LLS, and OES allow us to monitor the production of powder and to quantify them. The evolution of nanoparticle sizes, as can be characterized via Rayleigh-Mie ellipsometry (Refs. 13 and 14) or cavity ringdown spectroscopy, ${ }^{20}$ is beyond the scope of this paper.

In Table I we give the results of the ILSS and profilometric measurements, as well as the intensity of the LLS signal measured during processes A to E. The silane dissociation efficiency measured via ILSS monotonically increases from process $\mathrm{A}$ to $\mathrm{E}$ due to the increase in the gas residence time, $\tau_{\mathrm{r}}$, as $\tau_{\mathrm{r}} \propto p /\left(\left[\mathrm{H}_{2}\right]+\left[\mathrm{SiH}_{4}\right]\right)$ (since $\left[\mathrm{SiH}_{4}\right]$ is constant in our study, we have $\tau_{\mathrm{r}} \propto p c$ ). The gas residence time is of the order of the second and increases by roughly a factor three from process A to E. While the estimated $R_{\mathrm{d}}^{\mathrm{e}}$ increases from 13.6 to $15.7 \AA / \mathrm{s}$ from process A to E, the $R_{\mathrm{d}}$ measured via profilometry is constantly equal to $10 \AA / \mathrm{s}$. This apparent contradiction is explained by the fact that the $\mathrm{SiH}_{4}$ molecules that are dissociated in excess are lost in secondary gas-phase reactions and are expelled from the reactor in the form of polysilane and powder, as confirmed by the LLS measurement (Table I). In Fig. 1 , we compare $R_{\mathrm{d}}^{\mathrm{e}}-R_{\mathrm{d}}$ with the intensity of the LLS signal, and show that the two independent detections of powder production are in good qualitative agreement. We calculate $c_{\mathrm{p}}=c(1-D)$, where $D$ is the silane depletion, assuming $D=\eta$ when $c \ll 100 \% .{ }^{18} c_{\mathrm{p}}$ is the crucial parameter to determine if the PECVD process will result in amorphous or microcrystalline film growth. ${ }^{18}$ Using

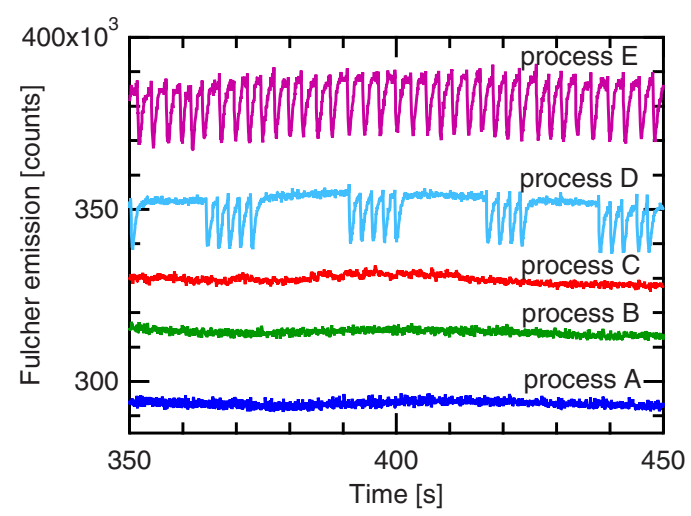

FIG. 2. (Color online) Time evolution of $\mathrm{I}_{\text {Ful }}$ measured via OES during processes A to E.

the procedure defined in Ref. 18, we determined via ILSS that, in our reactor, $\mu \mathrm{c}-\mathrm{Si}: \mathrm{H}$ material is deposited at the amorphous-to-microcrystalline transition when $1 \%<c_{\mathrm{p}}$ $<2.8 \%$. All the values of $c_{\mathrm{p}}$ in Table I are included within this interval, meaning that we were working in suitable conditions for the deposition of device-grade $\mu \mathrm{c}-\mathrm{Si}: \mathrm{H}$. The variations in $c_{\mathrm{p}}$ are very small because the increase in $\eta$ systematically compensates the increase in $c$, and this explains why the Raman crystalline fraction of the deposited films is almost constant despite the large variation in $c$.

Figure 2 shows the time evolution of the intensity of the Fulcher (600-630 nm) emission of molecular hydrogen, $\mathrm{I}_{\mathrm{Ful}}$, measured via OES. During processes A to $\mathrm{C}$, which are nearly-powder free, $\mathrm{I}_{\mathrm{Ful}}$ is constant, while its sharp oscillations during process $\mathrm{E}$ are likely related to the cycle of powder production and ejection from the reactor. In fact, $\mathrm{I}_{\mathrm{Ful}}$ is proportional to the electron density, which fluctuates due to the interaction between electrons and silicon clusters formed in the plasma. ${ }^{21,22}$ An interesting intermediate behavior is observed during process $\mathrm{D}$, which is characterized by a cyclic alternation of dusty and powder-free plasma conditions. Our results of OES plasma monitoring are in good qualitative agreement with the ILSS and LLS powder measurements presented in Fig. 1.

We repeated the full study at two higher values of the process pressure, namely, $p=5.5 \mathrm{mbar}$ and $p=7.0 \mathrm{mbar}$, and adapted the feed-in power density to keep comparable $\mathrm{I}_{c}$ and $R_{\mathrm{d}}=10 \AA / \mathrm{s}$. The input $\mathrm{SiH}_{4}$ flow remained unchanged. The input silane concentration was varied by changing the input $\mathrm{H}_{2}$ flow only. In Fig. 3 we plot the conversion efficiency of the solar cells versus $c$ for $p=4.5,5.5$, and 7.0 mbar. For a given $p$, the formation of powder increases with increasing $c$, as discussed above. For a given $c$, the formation of powder increases as $p$ increases. A monotonous increase in the efficiency is obtained both with increasing $c$ at a fixed $p$, and with increasing $p$ at a fixed $c$. In both cases, the variation in process parameters is such that secondary gasphase reactions are favored. We conclude that powder formation and, in general, secondary gas-phase reactions are not detrimental to the deposition of $\mu \mathrm{c}-\mathrm{Si}: \mathrm{H}$ at high rate. We even argue that some gas-phase reactions are beneficial to the high-rate deposition of device-grade $\mu \mathrm{c}-\mathrm{Si}: \mathrm{H}$ material. We point out that, for a given $c$, the improvement of cell performance with increasing $p$ could be partly due to additional effects, such as a reduced ion-bombardment on the growing surface. ${ }^{12}$ The best conversion efficiency we 


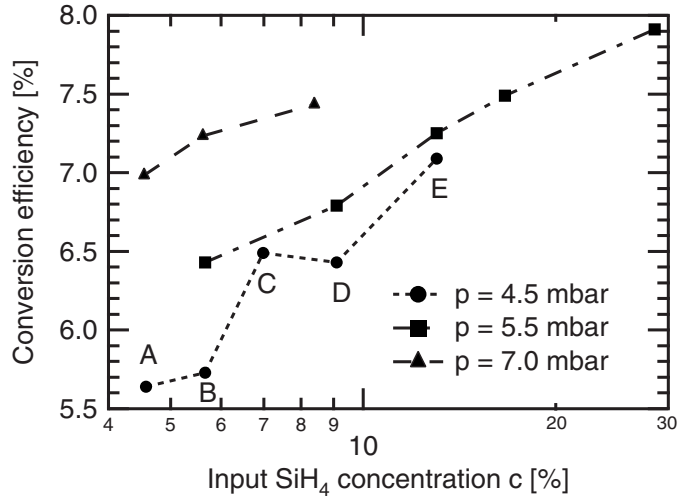

FIG. 3. Conversion efficiency of solar cells deposited at $R_{\mathrm{d}}=10 \AA$ / s using process pressures $p=4.5$ (corresponding to processes A to E), 5.5 and 7.0 mbar, vs input silane concentration. Lines are guides for the eye.

achieved in this study is $7.9 \%$. We used one of the best $\mu \mathrm{c}-\mathrm{Si}: \mathrm{H}$ cells in Fig. 3 as bottom cell for a a-Si:H/ $\mu \mathrm{c}-\mathrm{Si}: \mathrm{H}$ tandem device, and achieved $11.9 \%$ initial efficiency. The i-layers of the top and bottom cells were $250 \mathrm{~nm}$ and $2.5 \mu \mathrm{m}$ thick, respectively. No further optimization of the $\mu \mathrm{c}-\mathrm{Si}: \mathrm{H}$ or tandem solar cell design were undertaken.

The concept of powder formation covers a wide range of possible phenomena. In fact, the beginning of powder particle growth is a homogeneous process but not the following coagulation process leading to large size powder particles and resulting in an inhomogeneous plasma discharge, nonuniform deposition and plasma time-instability. ${ }^{23,24}$ However, it cannot be excluded that the early stage of powder formation has a beneficial effect on the material quality and on the performance of $\mu \mathrm{c}-\mathrm{Si}: \mathrm{H}$ devices. Powder is only one product of gas-phase reactions taking place in the volume of a plasma discharge but it is not yet clear in which way these reactions influence the material quality of the deposited film. In this paper, we have shown that the formation of powder during the PECVD process is not detrimental to the performance of $\mu \mathrm{c}-\mathrm{Si}: \mathrm{H}$ devices.

In summary, we have studied the plasma dynamic during deposition of $\mu \mathrm{c}-\mathrm{Si}: \mathrm{H}$ i-layers at a high rate. While maintaining a constant deposition rate of $10 \AA / \mathrm{s}$, we increased the input silane concentration and the process pressure, in order to favor the formation of powder. Powder is regarded here as a product of secondary gas-phase reactions that is expelled from the PECVD reactor. Using LLS, OES, and ILLS we show that powder-rich processes are favorable for the deposition of device-grade $\mu \mathrm{c}-\mathrm{Si}: \mathrm{H}$. Our conclusion is supported by state of the art single-junction and multijunction devices having initial conversion efficiencies of $7.9 \%$ and $11.9 \%$, respectively.

The authors would like to thank S. de Wolf for helpful discussions. Furthermore, the authors gratefully acknowledge support from the EU-Project 'Athlet' under the Contract No. 019670 and from the Swiss Federal Office for Energy (OFEN) under the Contract No. 101191.

${ }^{1}$ K. Yamamoto, A. Nakajima, M. Yoshimi, T. Sawada, S. Fukuda, T. Suezaki, M. Ichikawa, Y. Koi, M. Goto, T. Meguro, T. Matsuda, M. Kondo, T. Sasaki, and Y. Tawada, Prog. Photovoltaics 13, 489 (2005).

${ }^{2}$ J. Meier, R. Flückiger, H. Keppner, and A. Shah, Appl. Phys. Lett. 65, 860 (1994).

${ }^{3}$ F. Finger, P. Hapke, M. Luysberg, R. Carius, H. Wagner, and M. Sheib, Appl. Phys. Lett. 65, 2588 (1994).

${ }^{4}$ A. Shah, P. Torres, R. Tscharner, N. Wyrsch, and H. Keppner, Science 285, 692 (1999).

${ }^{5}$ M. Kondo, M. Fukawa, L. Guo, and A. Matsuda, J. Non-Cryst. Solids 266-269, 84 (2000)

${ }^{6}$ Y. Nakano, S. Goya, T. Watanabe, N. Yamashita, and Y. Yonekura, Thin Solid Films 506-507, 33 (2006).

${ }^{7}$ B. Strahm and Ch. Hollenstein, J. Appl. Phys. 107, 023302 (2010).

${ }^{8}$ G. Bano, P. Horvath, K. Rozsa, and A. Gallagher, J. Appl. Phys. 98, 013304 (2005).

${ }^{9}$ B. Rech, T. Roschek, T. Repman, J. Müller, R. Schmitz, and W. Appenzeller, Thin Solid Films 427, 157 (2003).

${ }^{10}$ A. Gordijn, L. Hodakova, J. K. Rath, and R. E. I. Schropp, J. Non-Cryst. Solids 352, 1868 (2006).

${ }^{11}$ Y. Mai, S. Klein, R. Carius, J. Wolff, A. Lambertz, F. Finger, and X. Geng, J. Appl. Phys. 97, 114913 (2005).

${ }^{12}$ G. Bugnon, A. Feltrin, F. Meillaud, J. Bailat, and C. Ballif, J. Appl. Phys. 105, 064507 (2009).

${ }^{13}$ P. Roca i Cabarrocas, J. Non-Cryst. Solids 266-269, 31 (2000).

${ }^{14}$ P. Roca i Cabarrocas, Th. Nguyen-Tran, Y. Djeridane, A. Abramov, E. Johnson, and G. Patriarche, J. Phys. D: Appl. Phys. 40, 2258 (2007).

${ }^{15}$ J. Perrin, J. Schmitt, Ch. Hollenstein, A. A. Howling, and L. Sansonnens, Plasma Phys. Controlled Fusion 42, B353 (2000).

${ }^{16}$ G. Parascandolo, G. Bugnon, A. Feltrin, and C. Ballif, Prog. Photovoltaics 18, 257 (2010).

${ }^{17}$ R. Bartlome, A. Feltrin, and C. Ballif, Appl. Phys. Lett. 94, 201501 (2009).

${ }^{18}$ B. Strahm, A. A. Howling, L. Sansonnens, and Ch. Hollenstein, Plasma Sources Sci. Technol. 16, 80 (2007).

${ }^{19}$ R. Bartlome, B. Strahm, Y. Sinquin, A. Feltrin, and C. Ballif, "Laser applications in thin-film photovoltaics," Appl. Phys. B: Lasers Opt. (to be published).

${ }^{20}$ T. Nagai, A. H. M. Smets, and M. Kondo, J. Non-Cryst. Solids 354, 2096 (2008)

${ }^{21}$ A. Bouchoule, A. Plain, L. Boufendi, J. Ph. Blondeau, and C. Laure, J. Appl. Phys. 70, 1991 (1991).

${ }^{22}$ E. V. Johnson, Y. Djeridane, A. Abramov, and P. Roca i Cabarrocas, Plasma Sources Sci. Technol. 17, 035029 (2008).

${ }^{23}$ A. A. Fridman, L. Boufendi, T. Hbid, B. V. Potapkin, and A. Bouchoule, J. Appl. Phys. 79, 1303 (1996).

${ }^{24}$ Ch. Hollenstein, Plasma Phys. Controlled Fusion 42, R93 (2000). 